\title{
Incidence and coincidence of hiatus hernia
}

\author{
RONALD B. PRIDIE \\ From the Radiodiagnostic Department, The London Hospital, Whitechapel, London
}

The frequency of hiatus hernias found incidentally during routine barium meal examinations has been reported on many occasions (Eisen, 1938; Levy and Duggan, 1941; Mendelsohn, 1946; Root and Pritchett, 1938; and Ritvo, 1930), and varies between $0.8 \%$ and $2.9 \%$. When the abdominal pressure is increased by any method during the examination, the incidence rises to between $2.1 \%$ and $11.8 \%$ (Boyd, Harris, Butler, and Donaldson, 1956; Carmichael, 1959; Conway-Hughes, 1956; Sim, 1964; and Hafter, 1958). Stein and Finkelstein (1960), Texter, Van Derstappen, Chejfec, Chvojka, Vidinli, Barborka, and Bundesen (1962), and Wolf and Guglielmo (1957) have shown that even more hernias can be demonstrated if the patient is given barium to swallow when in the prone position with the abdomen compressed.

\section{METHOD}

To find the incidence of hiatus hernia when each patient having a barium meal is given barium to swallow whilst lying prone, 500 consecutive barium meals were studied. All the examinations were done to establish the cause of abdominal pain believed to be due either to peptic ulceration or to gastric neoplasm. Meals which were given to confirm the presence of a clinically suspected hiatus hernia were not included in the 500 , nor were those merely to estimate progress of a known gastric ulcer or examinations on patients who had already had gastric surgery. If a hiatus hernia had not already been seen before completing each examination, a single mouthful of barium was given whilst the patient lay prone over a firm bolster some 9 in. in diameter. The barium was watched on the screen as it moved down the oesophagus, and the oesophageal peristaltic waves were examined particularly to see if they continued as far as the diaphragm or not. Gastro-oesophageal reflux was not diagnosed unless the oesophagus filled from below, that is, without giving barium in the prone position. A film was taken of the oesophagus after it had emptied as much as it would and a hiatus hernia was diagnosed only if a ring or groove as described by Maclean (1959) could be identified above the diaphragm and the mucosal pattern of the supradiaphragmatic pouch was continuous with that of the infradiaphragmatic portion of the stomach. When doubt existed on the evidence of either the screening or the film about the presence of a hernia none was reported.
RESULTS

The frequency of hiatus hernias for each decade is shown in Table I. The overall incidence is $29.6 \%$. Twenty-one per cent of the males had hernias and $39 \%$ of the females. More women than men had hernias in each age group. The frequency of hernias rose with age from $9 \%$ in those under 40 to $69 \%$ in patients over 70 years of age.

Gastro-oesophageal reflux occurred in 57 of the $148(38 \%)$ patients with hiatus hernia and was seen in 41 women ( $45 \%$ of those with hernias) and 16 men $(29 \%)$.

TABLE I

\begin{tabular}{|c|c|c|c|c|c|c|c|}
\hline \multicolumn{8}{|c|}{ INCIDENCE OF HIATUS HERNIA IN EACH DECADE } \\
\hline \multirow[t]{2}{*}{ Age (yr.) } & \multicolumn{3}{|c|}{ With Hiatus Hernia } & \multicolumn{3}{|c|}{$\begin{array}{l}\text { Without Hiatus } \\
\text { Hernia }\end{array}$} & \multirow[t]{2}{*}{ Total } \\
\hline & Male & s Females & Total & Males & Females & Total & \\
\hline $\begin{array}{l}\text { Under } 30 \\
30-39 \\
40-49 \\
50-59 \\
60-69 \\
70 \text { plus }\end{array}$ & $\begin{array}{r}1 \\
4 \\
12 \\
21 \\
11 \\
7\end{array}$ & $\begin{array}{r}2 \\
3 \\
20 \\
22 \\
29 \\
16\end{array}$ & $\begin{array}{r}3 \\
7 \\
32 \\
43 \\
40 \\
23\end{array}$ & $\begin{array}{r}26 \\
43 \\
44 \\
56 \\
33 \\
9\end{array}$ & $\begin{array}{r}12 \\
21 \\
42 \\
33 \\
32 \\
1\end{array}$ & $\begin{array}{l}38 \\
64 \\
86 \\
89 \\
65 \\
10\end{array}$ & $\begin{array}{r}41 \\
71 \\
118 \\
132 \\
105 \\
33\end{array}$ \\
\hline Total & 56 & 92 & 148 & 211 & 141 & 352 & 500 \\
\hline
\end{tabular}

Table II shows the coincidence of hiatus hernia with other lesions of the stomach and duodenum. Sixteen out of $66(25 \%)$ patients with duodenal ulceration had a hiatus hernia, but only three out of 41 patients with line gastric ulcers $(7 \%)$. One subject had both a duodenal and a gastric ulcer.

\section{DISCUSSION}

Of the several factors which could account for the higher incidence of hiatus hernia in this series compared with those of previous writers, the method of examination is probably the most important. Unless the patient is given barium to swallow after being placed prone over a pad, small hernias will not be visualized, as a light barium coating on the fundus of the stomach may be squeezed off the mucosa as it slides through the relatively tight hiatus 


\section{TABLE II}

COINCIDENCE OF HIATUS HERNIA WTH OTHER LESIONS

\begin{tabular}{|c|c|c|c|c|c|c|}
\hline \multirow[t]{2}{*}{$\begin{array}{l}\text { Lesions Other than } \\
\text { Hiatus Hernia }\end{array}$} & \multicolumn{3}{|c|}{$\begin{array}{l}\text { Patients With } \\
\text { Hiatus Hernia }\end{array}$} & \multicolumn{3}{|c|}{$\begin{array}{l}\text { Patients Without } \\
\text { Hiatus Hernia }\end{array}$} \\
\hline & Male & Females & Total & Males & Females & Total \\
\hline Gastr & 1 & $3^{1}$ & $4^{1}$ & $21^{1}$ & 16 & $37^{1}$ \\
\hline Duodenal ulcer & 10 & $6^{1}$ & $16^{1}$ & $43^{1}$ & 7 & $50^{1}$ \\
\hline Carcinoma & 2 & 2 & 4 & 7 & 2 & 9 \\
\hline None & 43 & 82 & 125 & 141 & 116 & 257 \\
\hline
\end{tabular}

1 One man and one woman each had both a gastric ulcer and a duodenal ulcer.

in the diaphragm. Also, unless a supradiaphragmatic portion of stomach is distended with swallowed air after sliding through the diaphragmatic hiatus it will not be recognizable. When using a prone swallow technique, care must be taken that a normal phrenic ampulla is not mistaken for a hiatus hernia as it may be if films of the full oesophagus are taken, although identification of the oesophageal ring or groove (Maclean, 1959) should prevent such confusion. Films of a hiatus hernia taken after the oesophagus has emptied are normally easy to interpret. The upper border of the hernia is usually rounded and the mucosal folds are continuous with those of the infradiaphragmatic portion of the stomach. Insistence on both screen and film evidence of a hernia and the rejection of doubtful cases ensured that hiatus hernia was not diagnosed more frequently that it was present.

Many radiologists do not examine all their patients given barium meals in this way. 'A textbook of X-ray diagnosis' (edited by Shanks, 1958) by British authors suggests that it is only necessary to look for hiatus hernia when it is clinically indicated. However, this study shows that many will be missed if a swallow with the patient prone over a bolster is not done as part of every barium examination of the oesophagus, stomach, and duodenum.

The diagnosis of hiatus hernia was not made clinically in any of the 125 cases in which one was found. This must mean either that the lesion was silent, that the referring clinicians were inexpert diagnosticians, or that hiatus hernia can produce symptoms indistinguishable from peptic ulcer and gastric carcinoma. The referring clinicians in this series consisted of a large number of consultant physicians and surgeons with their registrars at two London teaching hospitals, who might be expected to be at least as good as any other group of doctors at diagnosing hiatus hernia. The series contained $13.2 \%$ of duodenal ulcers which is a similar proportion to almost all other series (Sim, 1964) so that the diagnostic acumen of those referring the patients was well up to average in this respect. Lack of expertise in diagnosis is therefore probably not the reason for a large number of hiatus hernias being found in this series.

The series is similar in other respects to most of those reported from routine radiological examinations, so it is likely that the true incidence of hiatus hernia is no greater and that the large number found is due entirely to the technique employed. Nevertheless the question of the significance of these diaphragmatic hernias is still left open and whether they are asymptomatic or whether they cause symptoms which mimic peptic ulcers and neoplasms.

SUMMARY

Using a barium swallow with the patient prone over a bolster, hiatus hernias were demonstrated in $30 \%$ of patients suspected of peptic ulceration or gastric neoplasm who were referred for barium meal examination.

I should like to thank Dr. R. S. Murray for his helpful criticism and Miss B. Matthews for her great assistance secretarially.

\section{REFERENCES}

Boyd, J. W., Harris, J. R., Butler, E. B., and Donaldson, S. W. (1956) Evaluation of the various methods of demonstrating a hiatus hernia. Amer. J. Roentgenol., 75, 262-268.

Carmichael, J. H. E. (1959). An evaluation of the toe-touch position in the diagnosis of hitatus hernia. Brit. J. Radiol., 32, 479-482.

Conway-Hughes, J. H. L. (1956). Oesophageal reflux: an analysis of 453 consecutive barium meal examinations. Ibid., 29, 331-334.

Eisen, D. (1938). Oesophageal hiatus hernia (with special reference to its $X$-ray diagnosis). Canad. med. Ass. J., 39, 207-213.

Hafter, E. (1958). Hiatal hernia: Its diagnosis and clinical significance. Amer. J. dig. Dis., 3, 901-915.

Levy, M. D., and Duggan, L. B. (1941). Hiatus hernia of the stomach incidence, symptoms and medical management in 1,220 gastro-intestinal cases. S. Afr. med. J., 34, 351-357.

Maclean, C. D. T. (1959). Radiological assessment of the gastrooesophageal junction. Brit. J. clin. Pract., 13, 849-856.

Mendelsohn, E. A. (1946). Hiatus hernia of the stomach as a source of gastro-intestinal bleeding. Radiology, 46, 502-506.

Ritvo, M. (1930). Hernia of the stomach through the esophageal orifice of the diaphragm. J. Amer. med. Ass., 94, 15-21.

Root, J. C., and Pritchett, C. P. (1938). Diaphragmatic hernia. Cleveland Clin. Quart., 5, 203-216.

Shanks, S. C. (1958). In A Textbook of X-ray Diagnosis, by British Authors, 3rd Ed., pp. 265-285. Edited by S. C. Shanks and P. Kerley. Lewis, London.

Sim, G. P. G. (1964). An evaluation of tests for hiatus hernia. Brit. J. Radiol., 37, 781-787.

Stein, G. N., and Finkelstein, A. (1960). Hiatal hernia: roentgen incidence and diagnosis. Amer. J. dig. Dis., 5, 77-87.

Texter, E. C., Jr., Van Derstappen, G., Chejfec, G., Chvojka, V. E., Vidinli, M., Barborka, C. J., and Bundesen, W. E. (1962). Criteria for the diagnosis of hiatal hernia. Arch. intern. Med., 110, 827-836.

Wolf, B. S., and Guglielmo, J. (1957). The roentgen demonstration of minimal hiatus hernia. Med. Radiogr. Photogr., 33, 90-92. 